$\gg$ epad

Vol. 2, N. 1, Abril/2018

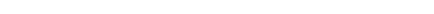




\title{
GERAÇÃO X, Y E BABY BOOMERS: Um Desafio Atual para uma Organização do Segmento Tecnológico
}

\section{GENERATION X, Y AND BABY BOOMERS: A current challenge for an organization of tecnologic segment}

Moisés Phillip Botelho

FATEC - Faculdade de Tecnologia Senai MT https://orcid.org/0000-0003-0690-8370

Ederson Fernandes de Souza

FATEC - Faculdade de Tecnologia Senai MT https://orcid.org/0000-0002-2207-3695

Leni Fátima Ferreira

FATEC - Faculdade de Tecnologia Senai MT https://orcid.org/0000-0001-7955-0539

Rosicley Nicolau de Siqueira FATEC - Faculdade de Tecnologia Senai MT https://orcid.org/0000-0001-7944-1084

\section{RESUMO}

A globalização estimulou mudanças organizacionais, assim conhecer como as gerações se comportam, em especial Baby Boomers, $\mathrm{X}$ e $\mathrm{Y}$, torna-se estratégico para a produtividade e rentabilidade das empresas. E ao identificar as diferenças e particularidades, pode-se realizar a gestão do capital humano com maior eficiência na delegação de tarefas. Diante disso, o objetivo deste trabalho é apresentar resultados prévios de uma pesquisa qualitativa sobre as percepções das gerações, Baby Boomers, X e Y, na empresa Plugmais Distribuidora de Informática e Telecomunicações, localizada em Cuiabá, Mato Grosso. O instrumento de pesquisa utilizado foi um questionário com perguntas fechadas de múltipla escolha, aplicado a 23 colaboradores da empresa. Os resultados foram analisados com o suporte da escala Likert, com pontuação de 1 a 4 e indicaram que os participantes da pesquisa identificaram que a empresa em que trabalham desconsidera a rotatividade de pessoal um fator preocupante.

Palavras-chave: Estilo de administração, Gerações, Mundo do trabalho, Percepções.

\begin{abstract}
Globalization has stimulated organizational changes, this way getting to know how the generations behave, especially Baby Boomers, $\mathrm{X}$ and $\mathrm{Y}$, it becomes strategic for productivity and profitability of companies. And by identifying them through their differences, particularities of the generations, it is possible to carry out human capital management as a greater efficiency in the delegation of tasks. Therefore, the objective of this work is to present previous results of a qualitative research on the perceptions of the generations, "Baby Boomers, $\mathrm{X}$ and $\mathrm{Y}$, at Plugmais, a Computer and Telecommunication Distributors, located in Cuiabá, Mato Grosso. The research instrument used was a questionnaire with closed questions of
\end{abstract}


multiple choice, applied to 23 employees of the company. The results were analyzed with Likert scale support, with a score of 1 to 4 and indicated that the study participants identified that the company in which they work disregards staff turnover is a cause for concern.

Keywords: Administration style, Generations, World of work, Perceptions.

\section{INTRODUÇÃO}

A globalização estimulou mudanças organizacionais drásticas, dessa forma, é importante conhecer os comportamentos e as inter-relações das gerações que estão atuando juntas, neste século XXI, especialmente no ambiente corporativo. Diante disso, o objetivo deste artigo é identificar as percepções das diferentes gerações dos funcionários da empresa Plugmais Distribuidora de Informática e Telecomunicações, localizada em Cuiabá, Mato Grosso.

As percepções foram medidas partindo de 8 pontos relevantes: 1 - Estilo de administração; 2 - Turnover; 3 - Postura profissional; 4 - Posição na empresa; 5 - Foco no trabalho; 6 - Como é vista a liderança na organização; 7 - Qualidade de vida; 8 - Tecnologias. Diante disso, o tema que se desdobrou de tais percepções foi Gerações " $x$ ", " $y$ " e "Baby Boomers" como um desafio atual para uma organização do segmento tecnológico.

Para dar vazão a estas percepções o instrumento de pesquisa utilizado para coleta de dados foi um questionário com perguntas fechadas e de múltiplas escolhas, aplicado a 23 colaboradores. Os resultados foram analisados a partir da fundamentação teórica pertinente. A pesquisa faz uso da abordagem qualitativa e foi realizada entre janeiro e junho de 2017.

A empresa foco da pesquisa, Plugmais Distribuidora de Informática e Telecomunicações, começou suas atividades no ano de 1999, oferecendo serviços de soluções de conectividade na Empresa Kadri Informática, localizada em Cuiabá, Mato Grosso. No ano 2005, tornou-se uma empresa independente na distribuição de soluções profissionais de conectividade para projetos de diversos segmentos de empresas.

A empresa atua em todo o país na distribuição de produtos de TI, segurança e conectividade com valor agregado. Seus colaboradores participam, constantemente, de treinamentos ministrados diretamente por seus fornecedores, para que possam orientar os clientes e oferecer propostas com a melhor condição comercial e técnica com vendas consultivas.

\section{REFERENCIAL TEÓRICO}

Estilo de Administração e Turnover

As organizações são dirigidas de acordo com a personalidade, perspectivas e valores dos seus dirigentes estratégicos (LITTERER, 1980). Essas escolhas, na maioria das vezes, perpassam por aspectos culturais, econômicos e sociais, podendo afetar de forma negativa ou positiva as tomadas de decisões, pois decisões que funcionavam bem na década de 1980 e 1990, talvez, podem estar inadequadas para o tempo atual.

Um dos fatores que implica nesta possível inadaptabilidade, é que as configurações sociais e de mercado são outras e os espectros tecnológicos também, ou seja, o desenvolvimento tecnológico modificou e está modificando o estilo de administração, pois se criou e cria novos bens e serviços impulsionados pela inovação frenética e pulsante, que desdobra em novos hábitos de consumo (DRUCKER, 1999). 
E é neste contexto de mudanças que as empresas estão contratando candidatos, influenciados pelo consumismo e imediatismo das coisas, para ocupar as vagas disponíveis. Este cenário requer, do setor de gestão de pessoas, reflexão, estudo e entendimento de como está funcionando as diferentes gerações, que agora estão trabalhando juntas, com foco no alcance dos objetivos organizacionais (KNOB, 2016).

Esta configuração "geracional" das empresas no século XXI está trazendo alguns transtornos. Umm deles é o imediatismo das gerações mais jovens, ocasionando maior rotatividade (turnover), mas isso também está se desdobrando para colaboradores mais experientes e outros já na fase da melhor idade, fator preocupante (DE MATTOS, 2011).

A rotatividade de pessoal é algo frequente nas empresas, pois ela corresponde à proporção de empregados que deixam a organização em um determinado período, ou o movimento em que um funcionário é substituído por um novo colaborador (AGAPITO, 2015). É essencial atentar que a rotatividade de pessoal deve ser acompanhada de perto, para que se possa identificar as causas e danos ao bom andamento da empresa.

É importante ressaltar que, a alta rotatividade de funcionários coloca em questão os investimentos em treinamento e a forma do processo de recrutamento e seleção, uma vez que indica que algo não está indo bem (GONZAGA, 1998). Outro fator preocupante é que a alta rotatividade de funcionários impede o aumento da produtividade, o ganho de mercado e a possibilidade de geração de novos empregos (ZARDIN PATIAS et al., 2014).

Mediante a isso, os gestores de pessoas devem analisar todos os indicadores que se relacionam com à rotatividade de funcionários em suas empresas, conhecer seus colaboradores e estar atentos à transição das gerações. Um dos pontos enfatizados por Drucker (1999) é que uma empresa é medida por números, mas quebra porque não cuida do seu coração, ou seja, as pessoas.

Linha do tempo das gerações

As remunerações mais atraentes e uma maior estabilidade no emprego, para algumas gerações, não são vistas como ganho potencial e garantia de permanência duradoura em uma determinada empresa (CAVAZOTTE, 2012). Esta contradição se dá devido a necessidade crescente de pessoas mais qualificadas para ocupar determinados cargos nas organizações, ocasionando assim, certa "arrogância profissional" nos candidatos com qualificação acima da média (VELOSO, 2012).

A busca por candidatos mais qualificados estimula os gestores, de diversas empresas, a oferecer mais recursos e benefícios para reter este ou aquele profissional de talento. Este desenho apresenta a distinção entre algumas gerações de pessoas, que estão disputando espaço, hoje, no mercado de trabalho (RUDGE et al., 2017).

Assim, tem-se, de um lado, um grupo que deseja valorização, oportunidade de desenvolvimento profissional, sem abrir mão da qualidade de vida. Do outro lado, um grupo que deseja crescimento rápido, desafios constantes e ambientes de trabalho flexível.

O Quadro 1 apresenta a linha do tempo dessas gerações "conflitantes":

\begin{tabular}{|c|c|}
\multicolumn{2}{|c|}{ Quadro 1. Linha do tempo das gerações } \\
Gerações & $\begin{array}{c}\text { Linha do } \\
\text { Tempo }\end{array}$ \\
\hline Baby Boomers & 1946 a 1967 \\
\hline Geração X & 1968 a 1979 \\
\hline Geração Y & 1980 a 1981 \\
\hline
\end{tabular}

Fonte. Adaptado de Veloso, Silva, Dutra (2012) e De Mattos (2011) 
Diante disso, há a necessidade de analisar a geração, que cada funcionário pertence, pois cada uma é influenciada por um contexto histórico e por uma formação cultural, social e econômica. Isso pode influenciar no seu comportamento, assim, ao conhecê-los é mais uma alternativa para traçar caminhos, mediar conflitos e desenvolver estratégias para integrar essas diferentes gerações.

Comparações das Gerações Baby Boomers, X e Y no mundo do trabalho

Há pontos positivos em ambientes multigeracionais dentro das organizações, como por exemplo, o trabalho conjunto das gerações Baby Boomers, X e Y. Mas há também grandes possibilidades de ocorrem tormentas. Essas tormentas podem acontecer devido a instalação de um cenário de competitividade, com o propósito de entregar resultados surpreendentes (PEREIRA; ALMEIDA; LAUX, 2006).

Algumas dessas gerações podem incorrer no erro de entregar resultados a qualquer custo, isso é um perigo para a saúde da empresa (DE MATTOS, 2011). Um perigo porque competir ao extremo sem analisar de que forma as relações interpessoais, entre equipe e gestores, estão alicerçadas, ou seja, quais ferramentas apoiam esta gestão, e como mediar as tormentas que acontecem e virão acontecer (KNOB, 2016; OLIVEIRA, 2009).

Caso isso não seja observado, alguns indicadores organizacionais podem ser afetados, desde a atração e retenção de colaboradores até a competitividade da empresa frente aos seus concorrentes. Fazer uso de forma assertiva do feedback é uma ferramenta estratégica, sempre levando em consideração as características dessas gerações que integram os processos, podendo ser utilizadas pela liderança (DE MALAFAIA, 2011; TEIXEIRA et al., 2010).

Isso é importante, pois cada geração vivenciou momentos diferentes na história, cresceram em um recorte de tempo distinto, particulares, ingressaram no mercado de trabalho em épocas diferentes e hoje dividem o mesmo ambiente organizacional (DE MALAFAIA, 2011).

A Geração Baby Boomers, por exemplo, se caracteriza por optar por emprego fixo e estável, tendo seus valores embasados na construção de uma carreia sólida, em especial, em uma mesma empresa, o foco destes é na experiência e competência. Os profissionais desta geração se preocupam em cumprir obrigações, em relação à atividade profissional, são disciplinados, primam pelo respeito à família e são leais e colaborativos no ambiente de trabalho (SMOLA; SUTTON, 2002; ZEMKE et al., 2000; VELOSO, 2016).

Em contrapartida, essa geração tem dificuldade em equilibrar a vida profissional com a vida pessoal e tem no trabalho a principal fonte para realização pessoal (OLIVEIRA, 2009). Uma característica importante dessa geração é que não são muito bons em gerenciar conflitos nas organizações, sendo isso uma contradição, pois se possuem uma carreira consolidada isso deveria ser simples para eles (CAVAZOTTE, 2012).

$\mathrm{Na}$ outra esfera, encontra-se a geração $\mathrm{X}$, pessoas que valorizara a religião, os rituais formais, o materialismo e possuem atitudes mais negativas em relação ao trabalho (PEREIRA et al., 2003). São desconfiadas, em relação às empresas onde trabalham, não compartilham o mesmo compromisso dos Baby Boomers (CAPPI; ARAUJO, 2015).

Ao contrário, membros da geração $X$ valorizam muito trabalhar para si próprios e tratam a autoridade de maneira informal, e procuram uma hierarquia menos rigorosa (SMOLA; SUTTON, 2002; OLIVEIRA, 2009). Outro fator a se considerar, apreciam o dinheiro, mas querem obter equilíbrio em sua vida pessoal. Pode-se esperar dessa geração longas jornadas de trabalho, e em troca, desejam ganhar experiência e treinamento (CONGER, 1998). 
No Brasil, a geração X vivenciou o primeiro período do regime ditatorial marcado pela censura, cautela, desconfiança e cinismo (DE MATTOS, 2011). Todavia, são consideradas pessoas com maior autoconfiança e maior empreendedorismo, e praticidade na resolução de problemas, devido às turbulências que vivenciaram (CAPPI, ARAUJO, 2015).

Já a geração Y é constituída pelos nativos digitais (SANTAELLA, 2004), são pessoas que cresceram "inundadas" pela tecnologia e utilizam com muita frequência aparelhos digitais, com desenvoltura, em especial o computador e os celulares multifuncionais, e participam ativamente de redes sociais, de forma simultânea (XAVIER, 2011).

É considerada a primeira geração imersa na interatividade tecnológica, mesmo com as rápidas mudanças, perpetuadas por diversas inovações, nas mídias virtuais entre outras, isso não assusta esta geração. Isso acontece porque as outras gerações tiveram que ser inseridas no processo de "transição tecnológica", complexa, porém rápida, de uma forma nem tanto agradável (OLIVEIRA, 2009).

Para a geração Y essa "transição" foi menos impactante, pois por terem nascido no meio deste processo, isso oportunizou a eles mais afinidade, quase que de forma imediata, em relação ao uso dos artefatos tecnológicos, comparativamente às gerações antecessoras, Baby Boomers e X (RUDGE et al. ,2017). Mesmo sendo uma geração considerada audaciosa, e por não se assustarem com os avanços tecnológicos, ela agrega no "currículo" alguns pontos de atenção.

Um destes pontos é a frustração, pois as pessoas desta geração ao não receberem tarefas desafiadoras, quando são contratadas por uma empresa, acabam ficando frustradas e abandonando o emprego, alegando desmotivação, colaborando para o aumento da rotatividade nas organizações (BOHLANDER; SNELL, 2015).

Dessa forma, isso implica em intensa e viciosa necessidade de desafios constantes, pois eles querem ser testados, para demonstrar a sua capacidade. No entanto, há problemas nisso, eles rejeitam o trabalho em equipe, são individualistas e não aceitam uma estrutura hierárquica rígida (RUDGE et al, 2017).

Embora sejam relutantes em obedecer à hierarquia da empresa e difíceis de gerir em certos casos, aspiram os seus gestores devido a clareza e a forma como gerem suas próprias atividades, ou seja, possuem certa flexibilidade e autonomia, com "pitadas de rebeldia", na execução de suas atividades profissionais e lideram habilmente as novas tecnologias digitais (VELOSO, 2012).

Diante disso, reter e desenvolver pessoas da geração $\mathrm{Y}$, torna-se uma estratégia significativa, pois essa geração já está integrada nas organizações, podendo ser os futuros líderes. Uma das estratégias adotadas por algumas empresas é a prática de horários flexíveis, planos de aceleração de carreiras e incentivos para programas de trainees (OLIVEIRA, 2009).

Os programas de trainees têm sido uma forma de motivar e reter os profissionais da geração Y, pois ao término do programa podem ocupar cargos de liderança na organização (TEIXEIRA et al., 2010). Essa geração gosta de receber feedbacks, de todos os colaboradores com os quais se relacionam em suas atividades profissionais, devido ao seu forte desejo de crescimento de forma rápida e ágil (KNOB, 2016).

Para a geração Y é comum ter a atitude de procurar seus líderes para avaliar seu desempenho, mas de maneira informal. Na contramão disto, as pessoas da geração Baby Boomers almejam um feedback formal, semestral ou anual, que demonstre pontos de melhoria a curto, médio e longo prozo (FILENGA; VIEIRA, 2010).

Isso ocorre porque tanto os indivíduos das gerações $\mathrm{X}$ quanto da Baby Boomers gostam de assimilar novas habilidades no trabalho, enquanto os da geração Y valorizam a ascensão rápida da sua carreira profissional (CENNAMO; GARDNER, 2008; ZEMKE, RAINES, FILIPCZAK, 2000). 
As preferências em assimilarem novas habilidades, aprendizagens e desenvolvimento profissional para os Baby Boomers são estimuladas pela necessidade de reforçar seu valor e identidade profissional (VIEIRA, 2010). Para a geração $\mathrm{X}$, diz respeito à preocupação em se manterem empregados, e para a geração Y, ocorre por causa da busca da realização de um estilo de vida desejado (ZEMKE et al., 2000).

Observa-se que todas as gerações apresentadas têm seu espaço no mercado de trabalho, sendo assim, o profissional de Gestão de Recursos Humanos tem papel fundamental na organização, pois ele deve lançar mão de estratégias para reter e manter os talentos nas organizações, uma vez que compreende que cada geração tem características diferentes que atendem determinados direcionares estratégicos da empresa.

Segundo exemplificação, pode-se indicar que a Geração Baby Boomers atuaria, de forma significativa, no setor de planejamento de uma empresa. Enquanto a geração $X$ poderia atuar na definição do orçamento de uma organização, e a geração Y poderia ser considerada aqueles que partem para a ação que faz acontecer (JORNAL DA GLOBO, 2010). Mas é certo afirmar que não importa de qual geração as pessoas sejam, todas podem desenvolver bem seus papéis, desde que tenham preparo e as ferramentas adequadas.

\section{PROCEDIMENTOS METODOLÓGICOS}

A pesquisa em questão se faz necessária devido à carência de estudos realizados na cidade de Cuiabá, Mato Grosso, voltados para o atual desafio em gerir gerações diferentes dentro do ambiente organizacional. Pois é importante identificar se o que relata a literatura, sobre o tema em questão, é pertinente para as empresas instaladas na capital mato-grossense, ou seja, se as premissas dos estudos científicos se estratificam e se desdobram em premissas confirmadas por estudos regionais.

A princípio, pretendia-se fazer uso da pesquisa quantitativa, mas percebeu-se que esta não seria adequada, pois ao tratar percepções individuais, do público-alvo, a pesquisa qualitativa ofereceria subsídios adequados e pertinentes. $\mathrm{O}$ trabalho não pretende apresentar uma nova teoria, mas sim fazer uso do referencial teórico e de pesquisa de campo para aliar o teórico com o empírico. Na Figura 1, pode-se identificar o fluxo de trabalho que foi seguido.

Figura 1. Fluxo de trabalho a ser realizado
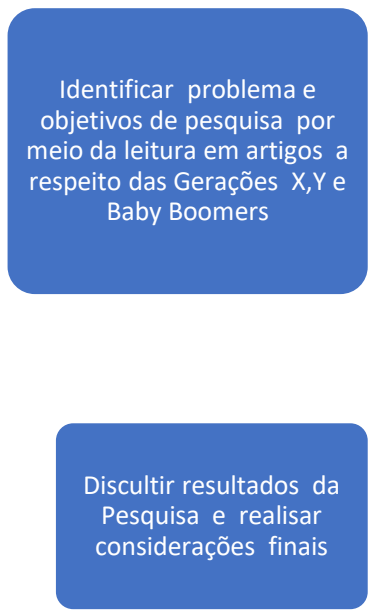
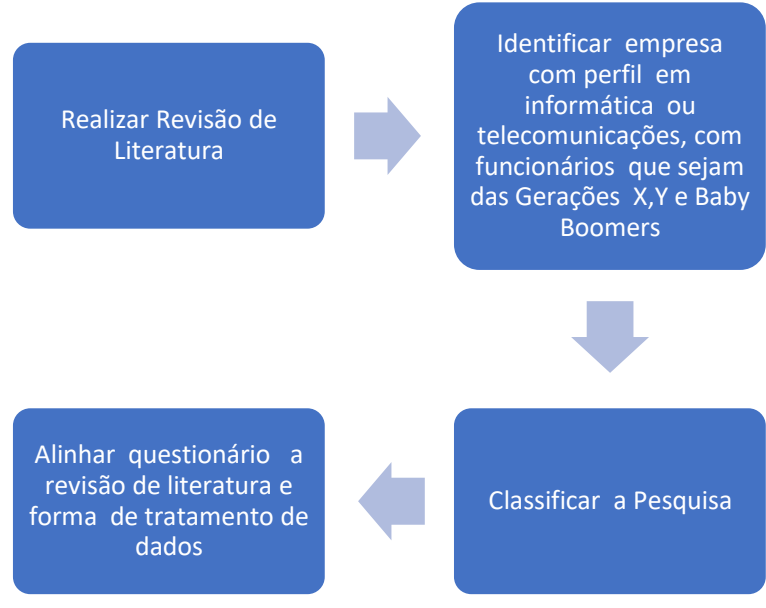

Fonte. Elaborado pelos Autores (2017) 
Para se ter maior afinidade com informações relacionadas às Gerações X, Y e Baby Boomers, optou-se em pesquisar artigos no Google acadêmico, jornais e livros. A maior parte das referências de pesquisa estão entre os anos de 2012 a 2016, fato que favorece uma revisão de literatura com informações atualizadas.

Sendo assim, para a realização da pesquisa foi utilizado o método qualitativo, e o instrumento que deu suporte foi um questionário com perguntas fechadas, de múltipla escolha, estruturados na escala Likert, com pontuação entre 1 a 4 . Foram obtidas 23 respostas, todos os respondentes são colaboradores da empresa Plugmais Distribuidora de Informática e Telecomunicações. Foi identificado que 15 dos respondentes do questionário são da geração Y, 7 da Geração X e apenas 1 funcionário pertence a geração Baby Boomers.

Cenário da pesquisa

A escolha foi pela empresa Plugmais Distribuidora de Informática e Telecomunicações que começou suas atividades no ano de 1999 no setor de soluções de conectividade na Empresa Kadri Informática, localizada em Cuiabá, Mato Grosso. Isso ocorreu por ser uma empresa do setor de informática e por ter aceitado a realização da pesquisa logo no primeiro contato, pois no percurso da pesquisa outras empresas já haviam recusado ser objeto de estudo.

No ano de 2005 a empresa se tornou independente na distribuição de soluções profissionais de conectividade para projetos de diversos segmentos de empresas.

O foco empresarial está no atendimento a provedores de serviços, revendas e empresas por intermédio de parcerias com distribuidores regionais, e prestadores e integradores de serviços nas áreas de: infraestrutura, telecomunicações, informática, segurança eletrônica, conectividade, Redes wireless, Sistemas de detecção e alarme de incêndio, Telefonia convencional e telefonia IP.

Atua em todo o país na distribuição de produtos de TI, segurança e conectividade com valor agregado. Seus colaboradores participam constantemente de treinamentos ministrados diretamente por seus fornecedores, para que possam orientar os clientes e oferecer propostas com a melhor condição comercial e técnica com vendas consultivas. A organização busca constantemente novas tecnologias que apresentem melhor qualidade, garantia e desempenho.

Questionário e Tratamento de dados

A pesquisa de campo contou com a participação de 23 colaboradores da organização, identificados previamente durante a pesquisa de campo como integrantes das Gerações X, Y e Baby Boomers, fator que favoreceu ao alinhamento da revisão de literatura os objetivos deste artigo. Para facilitar a pesquisa de campo, optou-se na utilização de um questionário com perguntas fechadas de múltipla escolha alinhadas à revisão de literatura, conforme Quadro 2

Segundo Alexandre (2003), em especial, para pesquisas quantitativas organizacionais a definição da escala de medida amplamente utilizada à escala de Likert, sendo que o número um, relaciona-se a maior relevância e número quatro nenhuma relevância, conforme o Quadro 3 . 


\begin{tabular}{|l|l|l|}
\hline \multicolumn{1}{|c|}{ Quadro 2. Método de trabalho para realizar perguntas } \\
\multicolumn{1}{|c|}{ Itens } & Diretrizes do Questionário & $\begin{array}{c}\text { Quantidade de } \\
\text { alternativas }\end{array}$ \\
\hline $\begin{array}{l}\text { Estilo da } \\
\text { Administração e } \\
\text { Turnover }\end{array}$ & 1- Estilo de Administração & 04 Alternativas \\
\hline & 2- Turnover & 04 Alternativas \\
\hline $\begin{array}{l}\text { Comparar as gerações } \\
\text { Baby Boomers, X, Y } \\
\text { para o mundo do } \\
\text { trabalho; }\end{array}$ & 3-Postura profissional & 03 Alternativas \\
\cline { 2 - 3 } & 5-Foçição na Empresa & 03 Alternativas \\
\hline & $\begin{array}{l}\text { 6-Relação como é vista a } \\
\text { Liderança na organização }\end{array}$ & 03 Alternativas \\
\hline & 7-Qualidade de Vida & 03 Alternativas \\
\hline & 8-Tecnologias & 03 Alternativas \\
\hline
\end{tabular}

Fonte. Autores (2017)

Quadro 3. Escala Likert com 4 pontos

\begin{tabular}{|c|c|c|c|}
\hline Muito Relevante & Relevante & Pouco Relevante & Nenhuma Relevância \\
\hline 1 & 2 & 3 & 4 \\
\hline
\end{tabular}

Fonte. Autores (2017)

Cada entrevistado estabeleceu notas de 1 a 4 para cada alternativa o que propiciou a identificação de quais itens estão entre Muito Relevante, Relevante, Pouco Relevante e Nenhuma Relevância.

\section{APRESENTAÇÃO E ANÁLISE DOS DADOS}

Será apresentado a seguir a consolidação dos dados obtidos na pesquisa das percepções acerca dos itens: 1 - Estilo de administração; 2 - Turnover; 3 - Postura profissional; 4 - Posição na empresa; 5 - Foco no trabalho; 6 - Como é vista a liderança na organização; 7 - Qualidade de vida; 8 - Tecnologias, conforme Quadro 4.

Nos Blocos 1 (Estilo de Administração) e 2 (Turnover), nota-se a divergência entre as gerações X e Y. De um lado, a geração X percebe que na empresa em que trabalha o estilo de liderança é pouco relevante. Esta percepção dialoga com o que a literatura aborda sobre a percepção dessa geração com o tema, ou seja, a sua desconfiança em relação à corporação em que trabalha. Tal desconfiança pode gerar um clima de "animosidade" entre os membros da geração X e as empresas, sendo assim, os gestores de pessoas devem identificar o porquê desta postura em relação a empresa.

Já quanto à geração $\mathrm{Y}$, observa-se que a empresa não está preocupada com as entradas e saídas de seus funcionários, possivelmente esta percepção é reforçada porque a empresa possui aproximadamente $65 \%$ de seus empregados identificados como pertencentes à geração Y. Isso acontece, segundo Rudge et al. (2017), devido as empresas terem dificuldade ou falta de expertise em lidar com os sentimentos, anseios e reações da geração Y, que é peculiar tanto no âmbito profissional quanto no pessoal (OLIVEIRA, 2009). 
Quadro 4. Consolidação dos dados da pesquisa

\begin{tabular}{|c|c|c|c|c|}
\hline ITENS & DIRECIONADORES & \multicolumn{3}{|c|}{ PERCEPÇÕES DAS GERAÇÕES } \\
\hline & & $\begin{array}{c}\text { BABY } \\
\text { BOOMERS }\end{array}$ & $\mathrm{X}$ & $Y$ \\
\hline $\begin{array}{c}\text { 1-ESTILO DE } \\
\text { ADMINISTRAÇÄO }\end{array}$ & $\begin{array}{l}\text { A. A organização é preocupada em saber } \\
\text { como seus funcionários pensam e comportam; } \\
\text { B. A organização vem modificando a forma de } \\
\text { buscar seus novos colaboradores; } \\
\text { C. O desenvolvimento da tecnologia tem } \\
\text { inspirado o estilo de administração; } \\
\text { D. Está sempre preocupada em desenvolver } \\
\text { novos produtos e aceita novos desafios. }\end{array}$ & RELEVANTE & $\begin{array}{c}\text { POUCO } \\
\text { RELEVANTE }\end{array}$ & $\begin{array}{c}\text { POUCO } \\
\text { RELEVANTE }\end{array}$ \\
\hline 2- TURNOVER & $\begin{array}{l}\text { A. A empresa sabe aproveitar e desenvolver } \\
\text { as qualidades e os conhecimentos específicos de } \\
\text { seus colaboradores e por isto tem baixa } \\
\text { rotatividade de pessoal; } \\
\text { B. A empresa preocupa-se em conhecer seus } \\
\text { colaboradores e em estar atendo na forma como } \\
\text { eles se relacionam, principalmente entre pessoas } \\
\text { da geração X e Y; } \\
\text { C. Contratação de novos funcionários impacta } \\
\text { na produção, uma vez que um colaborador novo } \\
\text { no período de treinamento e experiência onde } \\
\text { assimila baixa produtividade; } \\
\text { D. Quando ocorre alguma renovação nos } \\
\text { funcionários ocorre também a transição de uma } \\
\text { geração para outra, o que pode gerar conflito na } \\
\text { organização; }\end{array}$ & RELEVANTE & $\begin{array}{c}\text { NENHUMA } \\
\text { RELEVÂNCIA }\end{array}$ & $\begin{array}{c}\text { POUCO } \\
\text { RELEVANTE }\end{array}$ \\
\hline
\end{tabular}

Fonte. Elaborado pelos Autores (2017)

No Quadro 5, não ocorreu discrepâncias entre os respondentes, isso porque a maioria dos direcionadores está relacionado com interesses pessoais, ou seja, algo que está ligado diretamente com aspirações internas. É relevante considerar que o item 5, Foco no Trabalho, remete a uma avaliação dos pares, possivelmente ao tentar afirmar de forma negativa os respondentes estariam incluindo a si próprios como "pouco interessados", ou seja, não querem desqualificar a si mesmos.

Mas é importante destacar que há um percentual de influência nos resultados, ou seja, a geração Y é mais da metade dos funcionários da empresa, dessa forma, o perfil que está desenhado é que para "sobreviver" nessa organização é essencial aprender com este público em como fazer entregas e superar desafios.

Esta superação de desafios está associada com a capacidade de absorver e aprender de forma contínua. Tal aprendizado perpassa de como a estrutura organizacional oportuniza este crescimento. Um dos pontos essenciais para oportunizar este crescimento é a relação de líderes e liderados. No Quadro 6 este item foi percebido como relevante para os funcionários da Empresa Plugmais. 
Quadro 5. Consolidação dos dados da pesquisa

\begin{tabular}{|c|c|c|c|c|}
\hline ITENS & DIRECIONADORES & \multicolumn{3}{|c|}{ PERCEPÇÕES DAS GERAÇÕES } \\
\hline & & BABY BOOMERS & $X$ & Y \\
\hline $\begin{array}{l}\text { 3-POSTURA } \\
\text { PROFISSIONAL }\end{array}$ & $\begin{array}{l}\text { A. Os funcionários da empresa } \\
\text { assimilam seu trabalho com alta } \\
\text { prioridade em suas vidas; } \\
\text { B. Os funcionários da empresa } \\
\text { destacam-se pela dedicação e } \\
\text { experiência no trabalho; } \\
\text { C. Os funcionários da empresa são } \\
\text { confiantes e comprometidos com seus } \\
\text { valores pessoais; }\end{array}$ & RELEVANTE & RELEVANTE & RELEVANTE \\
\hline $\begin{array}{c}\text { 4-POSIÇÃO NA } \\
\text { EMPRESA }\end{array}$ & $\begin{array}{l}\text { A. Ter status e poder é importante } \\
\text { para os funcionários; } \\
\text { B. Os funcionários temem serem } \\
\text { substituídos pelas gerações seguintes; } \\
\text { C. Os funcionários são impulsivos, e } \\
\text { a hierarquia nem sempre é respeitada; }\end{array}$ & RELEVANTE & RELEVANTE & RELEVANTE \\
\hline
\end{tabular}

A. Os funcionários são focados no alcance de resultados;

B. Os funcionários são 5-FOCO NO TRABALHO comprometidos e fazer tudo a maneira da organização

$\begin{array}{lll}\text { RELEVANTE } & \text { RELEVANTE } & \text { RELEVANTE }\end{array}$

c. Os funcionários buscam novos desafios e desejam fazer tudo a sua maneira;

Fonte. Elaborado pelos Autores (2017)

Quadro 6. Consolidação dos dados da pesquisa

\begin{tabular}{|c|c|c|c|c|}
\hline ITENS & DIRECIONADORES & \multicolumn{3}{|c|}{ PERCEPÇÕES DAS GERAÇÕES } \\
\hline & & BABY BOOMERS & $x$ & $\bar{Y}$ \\
\hline $\begin{array}{l}\text { 6-COMO É VISTA A } \\
\text { LIDERANÇA NA } \\
\text { ORGANIZAÇÄO }\end{array}$ & $\begin{array}{l}\text { A. A liderança é vista como } \\
\text { sinônimo de comando e controle pelos } \\
\text { funcionários; } \\
\text { B. Os colaboradores valorizam as } \\
\text { competências em pessoas que estão } \\
\text { nos cargos de liderança; } \\
\text { c. Um líder com perfil multitarefa, } \\
\text { de controle, burocrático e de rotina é } \\
\text { mal visto na organização; }\end{array}$ & RELEVANTE & RELEVANTE & RELEVANTE \\
\hline 7-QUALIDADE DE VIDA & $\begin{array}{l}\text { A. Não é algo prioritário para os } \\
\text { funcionários da empresa; } \\
\text { B. Os colaboradores buscam o } \\
\text { equilibrio entre a vida pessoal e } \\
\text { profissional; } \\
\text { C. Os colaboradores tentam a } \\
\text { flexibilidade em suas atividades } \\
\text { profissionais para ser ter qualidade de } \\
\text { vida; }\end{array}$ & RELEVANTE & RELEVANTE & RELEVANTE \\
\hline 8-TECNOLOGIAS & $\begin{array}{l}\text { A. Os funcionários têm dificuldades } \\
\text { em lidar com tecnologias em geral; } \\
\text { B. Por terem contato com } \\
\text { tecnologias em sua adolescência, os } \\
\text { funcionários em geral tem maior } \\
\text { facilidade neste requisito; } \\
\text { C. Em geral, grande parte dos seus } \\
\text { funcionários nasceu tendo contato com } \\
\text { tecnologias, são nativos digitais. }\end{array}$ & RELEVANTE & RELEVANTE & $\begin{array}{c}\text { MUITO } \\
\text { RELEVANTE }\end{array}$ \\
\hline
\end{tabular}

Fonte. Autores (2017) 
A História já comprovou que líderes são intensos influenciadores e destruidores de talentos. Todos os respondentes percebem que a liderança da empresa é relevante para o alcance dos resultados. Outro item a ser destacado é a qualidade de vida, pois todos os respondentes identificam como relevante, assim este item deve ser analisado e tratado de perto.

Corroborando com toda a discussão deste tópico, o item 8, Tecnologias, foi percebido pela geração Y como muito relevante. Naturalmente é um resultado esperado por dois motivos. O primeiro, a empresa Plugmais atua no ramo da tecnologia e a geração Y está imersa neste universo. O segundo vai ao encontro do maior contingente de funcionários que empresa possui e possivelmente contrata, membros da geração Y.

Portanto, o retrato da empresa até aqui analisado é, irrefutavelmente, pertinente a geração Y. Ousa-se afirmar que, naturalmente, haverá uma "transição" ou mutação de perfil entre as gerações que atuam na Plugmais Distribuidora de Informática e Telecomunicações, pois as inter-relações oportunizam hibridizações, mas que conservam "certas essências" internas desta ou daquela pessoa.

\section{CONSIDERAÇÕES FINAIS}

A experiência de realizar uma imersão em uma empresa e identificar as percepções dos seus funcionários foi válida e possibilitou pensar em trabalhos futuros. A pesquisa pode comprovar que as premissas teóricas tanto na esfera global como particular foi corroborada pelos resultados obtidos na aplicação do questionário.

Dessa forma, não é estanque que a área de gestão de pessoas, no Brasil, "mergulhe" nesta temática e a transforme e uma área de estudos contundentes, pois, infelizmente, os gestores desconsideram integrar ao seu cotidiano de trabalho pesquisas operacionais que dialoguem com pesquisas básicas, que em contrapartida, podem se transformar em pesquisas aplicadas, como já acontece nos países desenvolvidos. Sendo assim, o ponto crucial que a pesquisa demonstrou como contundente e ponto de atenção foi que tanto a Geração X quanto a Y percebem que a empresa em que trabalham não está considerando a rotatividade de pessoal como um indicador importante.

\section{REFERÊNCIAS}

AGAPITO, Paula Rodrigues et al. Bem-estar no trabalho e percepção de sucesso na carreira como antecedentes de intenção de rotatividade. RAM. Revista de Administração Mackenzie, v. 16, n. 6, p. 71-93, 2015.

ALEXANDRE, João Welliandre Carneiro et al. Análise do número de categorias da escala de Likert aplicada à gestão pela qualidade total através da teoria da resposta ao item. Encontro Nacional De Engenharia De Produção, v. 23, p. 1-20, 2003.

BOHLANDE, George W; SNELL, Scott A. Administração de recursos humanos. 16. ed. São Paulo: Cengage, 2015.

CAPPI, Mariana Nitz; ARAUJO, Bruno Felix von Borell de. Satisfação no trabalho, comprometimento organizacional e intenção de sair: um estudo entre as gerações x e y. REAd. Revista Eletrônica de Administração (Porto Alegre), v. 21, n. 3, p. 576-600, 2015. 
CAVAZOTTE, Flávia de Souza Costa Neves; DA COSTA LEMOS, Ana Heloisa; DE AQUINO VIANA, Mila Desouzart. Novas gerações no mercado de trabalho: expectativas renovadas ou antigos ideais? Cadernos Ebape. br, v. 10, n. 1, p. 162-180, 2012.

CENNAMO, L; GARDNER, D. Generational differences in work values, outcomes and personorganization values f t. Journal of Managerial Psychology, 23, 891-906.

CONGER, Jay. Quem é a geração X. HSM Management, v. 11, n. 1, p. 128-138, 1998.

DE MALAFAIA, Gabriela Silva. Gestão estratégica de pessoas em ambientes multigeracionais. Disponível em: <http://www.inovarse.org/sites/default/files/T11_0452_2151.pdf>. Acesso em: 18 mar. 2017.

DE MATTOS, Carlos Alberto et al. Os desafios na transição da geração x para a y na empresa DORI LTDA. Revista Científica do Unisalesiano - Lins - SP, ano 2, n.4, jul/dez de 2011.

DRUCKER, Peter. Desafios gerenciais para o século XXI. São Paulo: Pioneira, 1999.

GONZAGA, Gustavo. Rotatividade e qualidade do emprego no Brasil. Revista de economia política, v. 18, n. 1, p. 120-140, 1998.

KNOB, Mônica Aline Strack. Percepção de carreira para a geração Y- um desafio para as organizações. São Paulo: RECAPE- revista de carreiras e pessoas. Volume VI número 03 setdez. 2016.

LITTERER, Joseph A. Introdução à administração. Rio de Janeiro: Livros Técnicos e Científicos, 1980.

OLIVEIRA, Sidnei. Geração Y: Era das Conexões, tempo de Relacionamentos. São Paulo: Clube de Autores, 2009.

PEREIRA, Rita de Cássia de Faria; ALMEIDA, Stefânia Ordovás De; LAUX, Fabiano Notti. Marketing de gerações: construção e teste de escala para avaliação da marca de refrigerante coca-cola por jovens na fase de transição entre as gerações X e Y. REAd-Revista Eletrônica de Administração, v. 12, n. 4, 2006.

RUDGE et al. Geração Y: um estudo sobre suas movimentações, valores e expectativas. ReCaPe - Revista de Carreiras e Pessoas, São Paulo, v. VII, n. 01, p. 406-421, jan./fev./mar./abr. 2017. Disponível em: https://revistas.pucsp.br/index.php/ReCaPe/article/view/32653/22579>. Acesso em: 05 fev. 2018.

SILVA, Augusto Santos; PINTO, José Madureira. Uma visão global sobre as ciências sociais. 11. ed. Porto Alegre: Edições afrontamento. 2001.

SMOLA, K. W., \& SUTTON, C. D. Generational differences: Revisiting generational work values for the new Millennium. Journal of Organizational Behavior, 2003,23, 363-382.

TEIXEIRA, G. M; SILVEIRA, A. C; NETO, C. P. S; OLIVEIRA, G. A. Gestão Estratégica de Pessoas. Rio de Janeiro: FGV Editora. 2010. 
VELOSO, Elza Fátima rosa; SILVA, Rodrigo Cunha da; DUTRA, Joel Souza. Diferentes gerações e percepções sobre carreiras inteligentes e crescimento profissional nas organizações. Revista Brasileira de Orientação Profissional, v. 13, n. 2, 2012.

VIEIRA, Almir Martins; FILENGA, Douglas. Faces e vicissitudes do trabalho: perspectivas históricas e contemporâneas. SIMPÓSIO DE EXCELÊNCIA EM GESTÃO E TECNOLOGIA, v. 7, 2010.

XAVIER, Antonio Carlos. Letramento digital: impactos das tecnologias na aprendizagem da Geração Y. Calidoscópio, v. 9, n. 1, p. 3-14, 2011.

ZARDIN PATIAS, Tiago et al. Custos da rotatividade de pessoal: evidências no setor de supermercados / Costs of staff turnover: evidence in the supermarket sector. RACE - Revista de Administração, Contabilidade e Economia, [S.1.], v. 14, n. 1, p. 143-170, dez. 2014. ISSN 21794936. Disponível em: 〈http://editora.unoesc.edu.br/index.php/race/article/view/4782〉. Acesso em: 05 fev. 2018. 